\title{
MANDIBULAR RAMUS LINEAR MEASUREMENTS AS AN INDICATOR OF CHRONOLOGICAL AGE AND SEX IN EGYPTIAN POPULATION
}

\author{
Shimaa M. Motawei", Ahmed MN. Helaly**, Wael M. Aboelmaaty ${ }^{* * *}$ and Khaled Elmahdy ${ }^{* * * *}$
}

\begin{abstract}
Background: The determination of age and sex is crucial for establishing human identity. The mandible is an accessible and durable bone that is very useful in this respect.

Aim: To assess the efficacy of measuring the mandible ramus length in the identification of age and sex in a group of Egyptians.

Subjects and Methods: The length of the ramus of the mandible was measured in lateral craniofacial scans of 213 individuals (99 males and 114 females) with an age range of 7-58 years using cone-beam computerized tomography (CBCT).

Results: Sexual dimorphism was not observed until age of 17 years in this sample. There was not found any significant differences in the length of the ramus of the mandible between males and females in the age range of 7 to less than 17 years $(\mathrm{P}$-value $=0.2495)$. There was a significant difference between males and females for the mean length of the ramus in the age range of 17 to 58 years (P-value $<0.0000)$. It predicts sex with an accuracy of $67 \%$. There was a positive correlation between and (age) and $\log _{e}$ (ramus length) ( $r=0.73$, P-value $<0.0001$ for females and $r=0.85$, $\mathrm{P}$-value $<0.0001$ for males). Therefore, it was possible to calculate each individual's age based on his or her mandible ramus length.
\end{abstract}

Conclusion: The mandibular ramus length is valuable in age estimation and less valuable in sex determination. Computerized tomography examination is a safe and an accurate procedure with minimal radiation exposure, and provides valuable precise information regarding mandible measurements.

KEY WORDS Mandible- Ramus length- Cone-beam computerized tomography (CBCT) - Age and sex identification- Egyptians

\footnotetext{
* Lecturer of Forensic Medicine \& Clinical Toxicology, Faculty of Medicine, Mansoura University, Egypt.

** Associate Professor of Forensic Medicine \& Clinical Toxicology, Faculty of Medicine, Mansoura University, Egypt. *** Lecturer of Oral and Maxillofacial Radiology, Faculty of Dentistry, Mansoura University, Egypt.

**** Dentist at the Ministry of Health and Population, Egypt.
} 


\section{INTRODUCTION}

Forensic identification using bone examination has been useful and reliable for a long time. It is easier, more accessible and relatively cheaper than complex methods of tissue identification. Furthermore, parts of bone have been increasingly found to be useful for answering questions related to the age and sex of an individual ${ }^{[1]}$.

The mandible is the hardest and strongest bone of the skull, and it exhibits a high degree of sexual dimorphism ${ }^{[2.3]}$. The mandible helps to identify the sex in living as well as dead individuals and human remains. In cadavers with an advanced degree of decomposition, burns or disfigurement, identification from tissue typing and DNA profiling becomes very difficult, and bone becomes a more reliable tool for identification in these cases ${ }^{[4]}$.

Identification of age is needed in criminal investigations and in civil cases, such as immigration, suspected violations of the laws regarding the age of marriage and in cases of immigrant foreigners who do not have valid identification documents. Age estimation is also required in other civil cases, such as requests of asylum or old-age pension, and for adoption purposes in cases of unaccompanied minors. Additionally, it is needed in investigations of mass disasters and war atrocities ${ }^{[5]}$.

The skull and hip bones are the most informative bones in terms of sex identification, as they are strongly affected by sex hormones during union and shaping of the bones at puberty. It is necessary to reduce the use of X-rays of the hip joint to avoid teratogenicity and to use and combine other methods for sex identification. Franklin and Cardini [6] believed that the developmental and functional aspects of the mandible render it an appropriate indicator of an individual's age and sex.

The mandible shows morphological changes related to size and remodeling during human growth. It has been found that there is a strong correlation between chronological age and mandible morphology, especially that of the ramus ${ }^{[7]}$. Additionally, ancestry and genetic factors are believed to modify bone age validation for chronological age determination. Thus, there is a need to establish national references for chronological age evaluation by anthropological indices before they can be used in court decisions ${ }^{[8]}$.

Cone-beam computerized tomography (CBCT) utilizes divergent $\mathrm{X}$-ray beams forming a cone to image bone and soft tissues. It provides much less radiation exposure than conventional $\mathrm{CT}$ and definitely less than ordinary X-ray imaging ${ }^{[9]}$.

This study aimed to determine the efficacy of the mandibular ramus length as a tool for identification of age and sex using CBCT imaging in a sample of Egyptians. Additionally, to establish reference values from the tested sample to determine age and sex in Egyptians by measuring the mandibular ramus length in lateral 3-dimensional craniofacial CBCT scans.

\section{SUBJECTS AND METHODS}

After approval of the study by the institutional research bureau of the Faculty of Medicine at Mansoura University, the length of the ramus of the mandible (the distance between the condyle superior (Cs) and the gonion (Go) was measured in lateral craniofacial scans of 213 individuals (99 males and 114 females) who underwent CBCT scans for various reasons (e.g. before root canal treatment) (Figure 1). The scans of the individuals, who ranged in age from 7 to 58 years (average 26.5 \pm 13.8 years), were examined. The male contributors were in age range $(7-58)$ years, an average of $25.88 \pm 13.64$ years. Female contributors were ( 7 - 58) years old with the average of $27.02 \pm 13.93$ years (Figure 2).

Subjects were carefully selected during the period from June 2016 to January 2017. Cases with a history of mandibular fractures or surgery were excluded. Additionally, cases with a history of 
orthodontic treatment, orthognathic surgery, head trauma or surgery, systemic disease, craniofacial microsomia or hereditary facial asymmetry were excluded from the study. Clinical examination was performed to exclude facial asymmetry or mandible abnormality in all subjects included in the study.

Patients' consents were obtained, and careful history taking and medical examination were performed. Imaging by CBCT was performed for the selected subjects by the same radiologist to avoid any technical error. The device used in this study was iCAT Next Generation (Imaging Science International, Hatfield, PA, USA). The imaging protocol used was as follows: Field of view, $16 \mathrm{~cm}$ diameter $13 \mathrm{~cm}$ height; voxel size, $0.25 \mathrm{~mm}$; and scan time, 14.7 seconds. The image analysis was performed with Anatomage Invivo 5.2 software (San Jose, California, USA).

The mandibular ramus length was measured from the Cs, the highest point of the condyle of the mandible, to the 'Go'; the outermost point at the junction between the body and the ramus of the mandible. The Go point was identified as the most lateral point at the bisector of the angle of the mandible. The Cs was identified as the highest point of a straight line drawn parallel to the horizontal plane passing through the superior surface of the mandibular condyle ${ }^{[10]}$.

Data were tabulated, coded and analyzed using the SAS computer program, version 14.1. Values were compared using the Welch two-sample t-test, student's t- tests, analysis of variance and the accuracy of the personal identification was assessed through general linear model analysis.

\section{RESULTS}

The results showed that sexual dimorphism of mandible ramus length was not seen until the age of 17 years (Table 1). There was no significant difference between males and females in the age range of $7-<17$ years $(\mathrm{P}$ value $=0.2495, \mathrm{t}=-1.17$ for student's t-test). On the other hand, men showed longer ramus lengths of the mandible than women at the age range of 17 to 58 years, and there was found a significant difference for the mean length of ramus of the mandible between men and women $(\mathrm{P}$-value $<0.001, \mathrm{t}=-10.59)$ (Figures 3 and 4$)$.

The discriminative function analysis showed that, based on the ramus length measurement using CBCT, it is possible to predict sex with an accuracy of $67 \%$ (Table 2). Furthermore, it is possible to predict sex with an accuracy of $82 \%$ when the length of ramus is greater than $5.00 \mathrm{~cm}$ and $89 \%$ when the length of the ramus is greater than $5.80 \mathrm{~cm}$.

\section{Age estimation}

Because sex has a very important role in development of the ramus length of the mandible, we calculated the regression lines for males and females separately. The original data showed that age and ramus length had an exponential curve and has heteroscedasticitic error. We made logarithmic transformation to obtain linearity, and then made square root transformation to stabilize the error variance (Figures 5\& 6). Based on the regression analysis, two formulas were developed to calculate the approximate chronological age using the length of the ramus of the mandible.

sqrt $\left(\log _{e}(\right.$ age_m $\left.)\right)=-0.092(\mathrm{SE}=0.112)+1.065$ $(\mathrm{SE}=0.064) \times \log _{e}\left(\mathrm{ramu}_{\mathrm{m}}\right.$ length in $\left.\mathrm{cm}\right)$ (For males) $\operatorname{sqrt}\left(\log _{e}(\right.$ age_f $\left.)\right)=-0.217(\mathrm{SE}=0.174)+1.209(\mathrm{SE}$ $=0.106) \times \log _{e}\left(\mathrm{ramu}_{\mathrm{f}}\right.$ length in $\left.\mathrm{cm}\right)$ (For females)

Based on the fitted models, from the Anova table and assuming normality, we calculate the probability, if a male has a mandibular ramus of $6.5 \mathrm{~cm}$ or more in length, he is $65 \%$ likely to be 30 years or older. Furthermore, we calculate $90 \%$ predict confident interval at the mandibular ramus $4.5 \mathrm{~cm}, 5.5 \mathrm{~cm}$ and $6.5 \mathrm{~cm}$ for males $(4.5 \mathrm{~cm}, 5.5 \mathrm{~cm}$ and $6.0 \mathrm{~cm}$ for females). If the ramus length is 6.5 $\mathrm{cm}$, then predict the mean age is 37.31 years old and $90 \%$ predict age confident interval $(23.03,62.58)$ 
If ramus length is $6.0 \mathrm{~cm}$, then predict mean age is 44.55 years old and $90 \%$ predict age confident interval $(22.83,92.75)$ (Table 3$)$.

Therefore, it was possible to calculate the individual's age given his or her ramus length. The results showed that sexual dimorphism is not seen until the age of 17 years, and based on mandibular ramus length measurements in this sample; it is possible to predict sex with an accuracy of $67 \%$. Also, there was a positive correlation between (age) and $\log _{e}$ (ramus length) (r=0.73, $\mathrm{P}$-value $<0.0001$ for females, and $\mathrm{r}=0.85$, $\mathrm{P}$-value $<0.0001$ for males).

TABLE (1): Mandibular ramus length in the contributors of the study according to their age and sex.

\begin{tabular}{|c|c|c|c|c|}
\hline & \multicolumn{2}{|c|}{$\begin{array}{c}\text { Age }(7-<17) \text { Years } \\
\quad \text { N. }=59\end{array}$} & \multicolumn{2}{|c|}{$\begin{array}{c}\text { Age (17- 58) Years } \\
\text { N. }=154 \\
\end{array}$} \\
\hline & $\begin{array}{l}\text { Males } \\
\text { N. }=\mathbf{2 6}\end{array}$ & $\begin{array}{l}\text { Females } \\
\text { N. }=33\end{array}$ & $\begin{array}{c}\text { Males } \\
\text { N. }=73\end{array}$ & $\begin{array}{c}\text { Females } \\
\text { N. }=81\end{array}$ \\
\hline Mandible Ramus Length (Mean \pm SD) & $4.79 \pm 0.43$ & $4.66 \pm 0.37$ & $6.044 \pm 0.42$ & $5.42 \pm 0.32$ \\
\hline $\begin{array}{c}\text { Test of Significance } \\
\text { (P - Value })\end{array}$ & \multicolumn{2}{|c|}{0.2495} & \multicolumn{2}{|c|}{$<0.001$} \\
\hline
\end{tabular}

N.; number, SD; Standard deviation. $P$-value is considered significant at $\leq 0.05$

TABLE (2): Discriminant analysis for sex differentiation from Mandible Ramus Length

\begin{tabular}{|c|c|c|}
\hline \multicolumn{3}{|c|}{ Linear discriminant function: Sex } \\
\hline Variable & $\mathbf{F}$ & $\mathbf{M}$ \\
\hline Constant & -39.00149 & -47.12827 \\
\hline Ramus Length & 15.00409 & 16.49339 \\
\hline Ratio & 0.3246 & 0.3333 \\
\hline
\end{tabular}

TABLE (3): Confidence intervals for Prediction of the mean age for different Lengths of the Ramus of the Mandible.

\begin{tabular}{|c|c|c|c|c|c|c|c|}
\hline $\begin{array}{c}\text { Length_ } \\
\text { ramus }\end{array}$ & Sex & predict & Lcl & Ucl & $\begin{array}{c}\text { Predict_mean } \\
\text { Age (year) }\end{array}$ & $\begin{array}{c}\text { Lcl_age (year) } \\
\mathbf{9 0 \%}\end{array}$ & $\begin{array}{c}\text { Ucl_age (year) } \\
\text { 90\% }\end{array}$ \\
\hline $\mathbf{4 . 5} \mathbf{~ c m}$ & F & 1.728 & 1.550 & 1.906 & 19.82 & 11.05 & 37.85 \\
\hline $\mathbf{5 . 5} \mathbf{~ c m}$ & F & 1.843 & 1.665 & 2.022 & 29.90 & 16.00 & 59.56 \\
\hline $\mathbf{6 . 0} \mathbf{~ c m}$ & F & 1.948 & 1.769 & 2.128 & 44.55 & 22.83 & 92.75 \\
\hline $\mathbf{4 . 5} \mathbf{~ c m}$ & M & 1.511 & 1.378 & 1.644 & 9.80 & 6.67 & 14.90 \\
\hline $\mathbf{5 . 5} \mathbf{~ c m}$ & $\mathbf{M}$ & 1.724 & 1.594 & 1.855 & 19.57 & 12.68 & 31.23 \\
\hline $\mathbf{6 . 5} \mathbf{~ c m}$ & $\mathbf{M}$ & 1.902 & 1.771 & 2.033 & 37.31 & 23.03 & 62.58 \\
\hline
\end{tabular}

Cm; centimeters, Lcl; lower confidence interval, Ucl; Upper confidence interval, \%; per cent, F; Female, M; Male. 


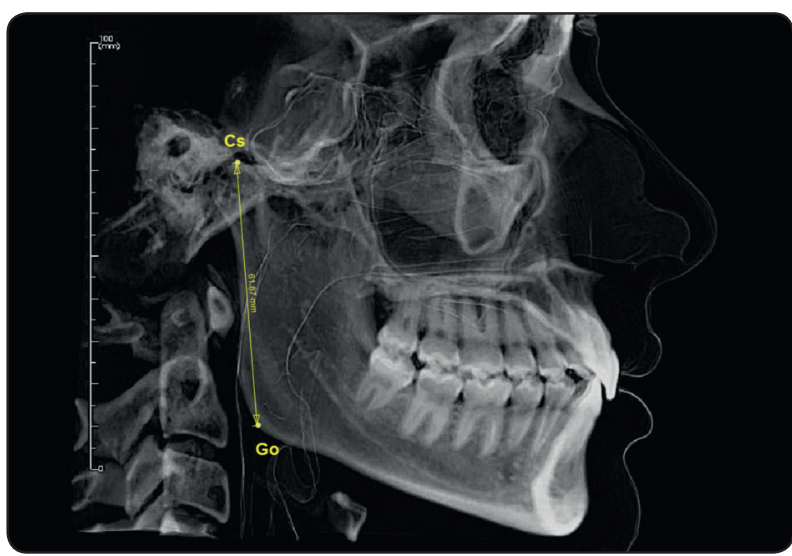

Fig. (1): Determination of the length of the ramus of mandible in millimeters by measuring the distance between condylion superior (Cs) and gonion (Go) in lateral cone beam computerized tomography (CBCT) scan.

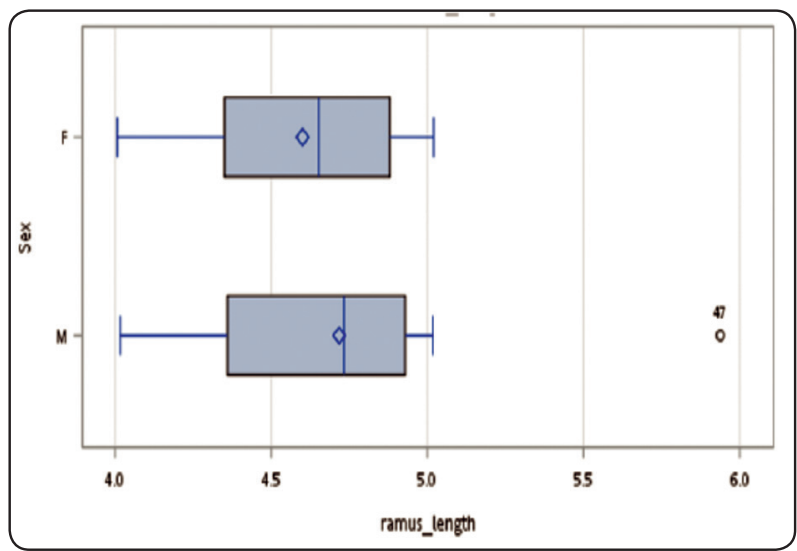

Fig. (3): Box-plot of ramus length in the age range 7 to $<17$ years, showing non-significant difference between males and females $(\mathrm{t}=-1.17, \mathrm{P}$ - value $=0.2495)$. M; males, F; females.

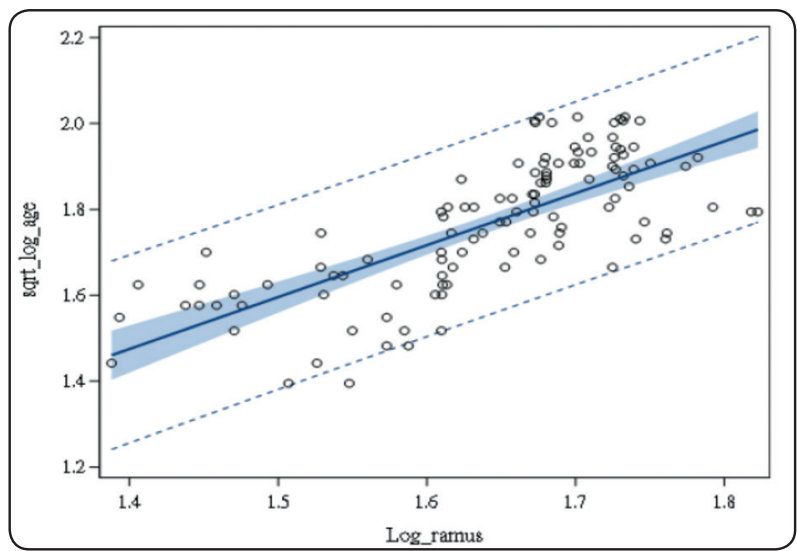

Fig. (5): Female fitted model, Mean Square Error (MSE) $=0.0114, \mathrm{r}=0.734$. The dash lines are predicting confidence interval, bold line is fitted regression line and dots are observations (after transformation).

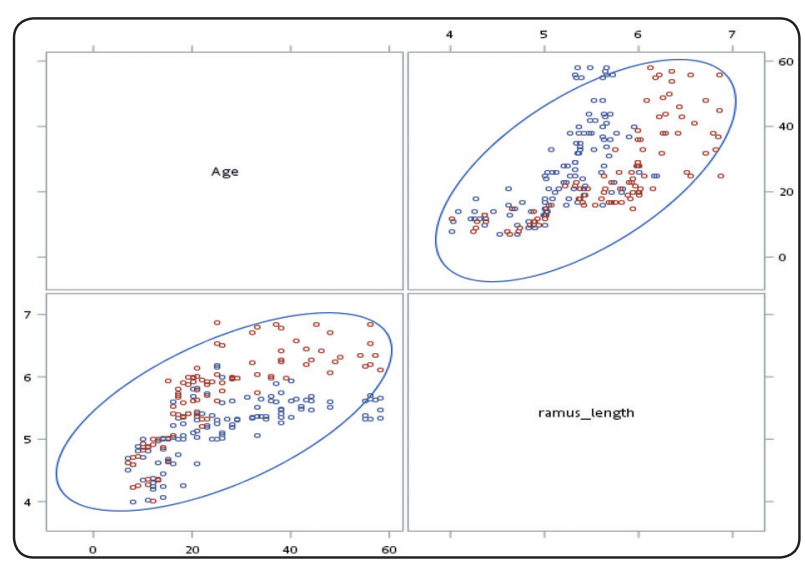

Fig. (2): Scatter plot for the raw data, red dot: male, blue dot: female.

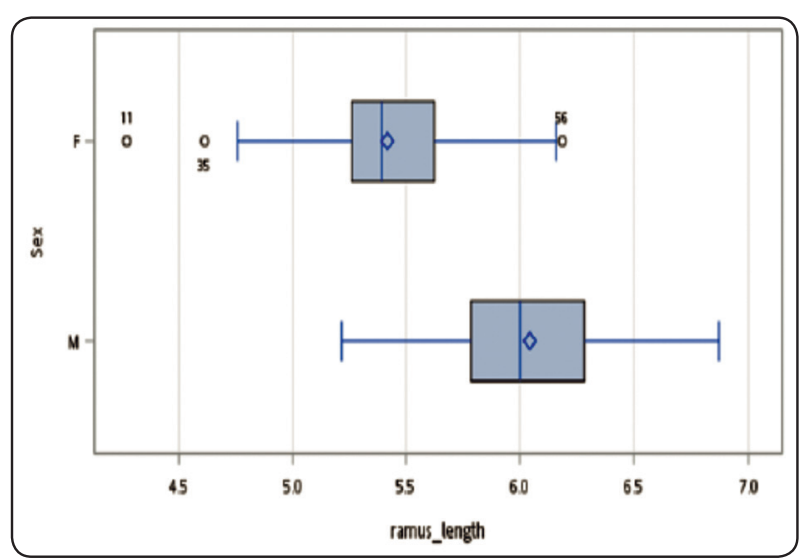

Fig. (4): Box-plot of ramus length in age range 17 to 58 years, showing highly significant difference between males and females $(\mathrm{t}=-10.59$, P- value $<0.001)$.

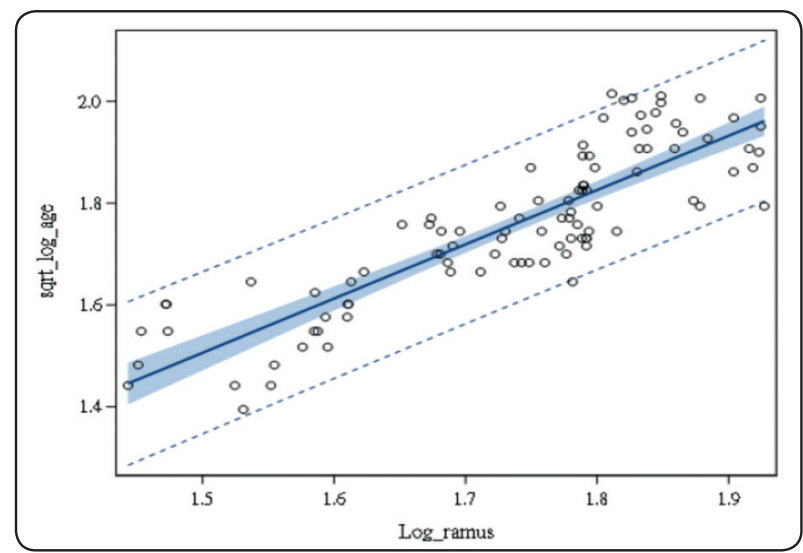

Fig. (6): Male fitted model, Mean Square Error (MSE) $=0.0061$, $\mathrm{r}=0.860$. The dash lines are predicting confidence interval, bold line is fitted regression line and dots are observations (after transformation). 


\section{DISCUSSION}

Skeletal identification has a long history in forensic anthropology. New methods are continuously introduced and routinely used methods are constantly evolving ${ }^{[1]}$.

Observation of the union of the epiphyses and the length of the diaphyses of long bones is the most frequently used method for identifying age, and an examination of the skull and hip bones is the most commonly used method for identifying sex. In this study, we used the mandible to identify both the age and sex of the individuals. We used three dimensional lateral craniofacial CT scans because this imaging modality is non-invasive and can be used for living and dead individuals and in both civil and criminal cases.

CT proved efficient, simple, rapid, reliable and safe as an imaging technique for forensic practice. CT has been demonstrated to be more accurate and more informative than routine $\mathrm{X}$-ray and conventional $\mathrm{CT}$ methods in forensic practice ${ }^{[9]}$. We found CBCT to be reliable and safe with minimal radiation exposure. It was efficient in determining sex with an accuracy of $67 \%$. There was no significant difference between males and females before the age of 17 years $(\mathrm{P}$ value $=$ 0.2438 ) in mandibular ramus length. One formula was developed to estimate age for males, and another formula was developed for females based on mandibular ramus length using the data in this sample of Egyptians.

These results are in accordance with those obtained by De Oliveira et al. ${ }^{[1]}$, who studied the length of the ramus of the mandible as an indicator of age and sex in a group of Brazilians. They found that sex could not be distinguished based on the mandibular ramus length measurement until the age of 18 years, and that measurement could be used to determine sex with an accuracy of only $54 \%$ using lateral cephalometric radiographs. This finding means that, compared with conventional CT or
X-ray imaging, CBCT increases the efficacy of the ramus length as a tool for sex identification.

This latest conclusion agrees with the results

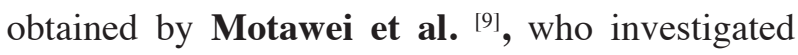
the frontal sinus using CBCT as a tool for sex differentiation and found that $\mathrm{CBCT}$ can be used to determine sex with an accuracy of $76.7 \%$. However, another group of researchers investigated the frontal sinus using plane X-ray scans and found that sex could only be determined in $64.6 \%$ of the study sample ${ }^{[12]}$. This difference in accuracy of sex differentiation may be attributed to the differences in ethnic groups of the studied populations, sample size, method and equipment used by the different investigators.

Holmes and Ruff ${ }^{[13]}$ stated that dietary factors affect human mandible development. Silva et al. ${ }^{[14]}$ and Ichijo et al. ${ }^{[15]}$ stated that ethnicity affects human mandible development and measurements. Filho et al. ${ }^{[16]}$ found that stressful lifestyles affect mandible development and function.

Our results agree with the results of More et al. [17], who analyzed 1000 dental X-rays of an Indian population to determine whether the length of the ramus of the mandible could be used to determine sex. They concluded that measuring the length of the mandible ramus is helpful for sex determination with an overall accuracy of $69 \%$.

Mandible shape and measurements are affected by sex hormones. Weinberg et al. ${ }^{[18]}$ observed a biological link between androgen exposure in prenatal period and the development of male facial characteristics.

Coquerelle et al. ${ }^{[19]}$ investigated whether the human mandible is sexually dimorphic during early postnatal development and adulthood. They concluded that males, by birth, have more advanced age-specific shapes than females and that sex differences decrease quickly between the ages of 4 and 14 years. Then, from puberty to adulthood, 
sexual dimorphism is observed and they are more at the ramus and the mental regions and are controlled by the surge of sex hormones ${ }^{[19]}$.

Kasperk et al. ${ }^{[20]}$ stated that certain skeletal sites have androgen-sensitive receptors that may contribute to the development of sex-related differences in skeletal morphology. Cattaneo et al. ${ }^{[21]}$ agreed with this statement and stated that it is helpful in age and sex determination in legal settings. This finding may explain the fact that some bones, such as hip bones and the skull are more accurate in sex determination than other bones, as these bones contain more of the androgensensitive receptors than facial bones, the sternum and other bones ${ }^{[22]}$.

Our results do not agree with the findings of Rai et al. ${ }^{[23]}$, who used measurements of the mandible in a group of Indians ranging from 7 to 20 years to determine sex. The investigators measured the length of the body of the mandible (the distance between the condylion superior and the gnathion), mandibular length (distance between the condylion and the gnathion), and mandible height (distance between the condylion and the gonion). They concluded that mandibular measurements provide information on age but not sex, as they found no difference between males and females in mandibular linear growth.

A study performed by Ishwar Kumar et al. ${ }^{[7]}$ in South Africa concluded that the length of the mandibular ramus generally has higher sexual dimorphism than any other mandibular segments (P-value $=0.000)$. The authors found that only the length of the right mandibular body differed significantly according to sex $(\mathrm{P}$-value $=0.040)$.

Hazari et al. ${ }^{[24]}$ reviewed articles that studied the mandible as a tool for age and sex identification. They stated that out of 16 radiographic studies, 14 showed that the adult mandible could be used with increased sensitivity to identify sex, and two studies showed insignificant results. Of the 20 morphometric studies of dry mandibles, 15 studies showed a positive correlation between sex and mandibular parameters, and five studies did not show any positive correlations between the two parameters.

This finding demonstrates that the mandible provides more accurate age and sex information when combined with other data.

\section{CONCLUSIONS}

In this study, sexual dimorphism in mandibular ramus length was not observed until the age of 17 years. Mandibular ramus length can be used to estimate sex with an accuracy of $67 \%$ using CBCT and can estimate age with a high degree of accuracy. Two separate formulae were derived to estimate age in males and in females.

The most commonly used procedures in the forensics of human remains are too invasive to use in living individuals. A multidisciplinary approach including forensic odontology will be useful in this respect, indicating the value of this study.

\section{Limitations and further recommendations}

This study can be repeated with a larger sample size. The height of the individual and other mandibular measurements, e.g. the total height of the mandible, the distance between the two mandibular rami, etc, can be combined for the age and sex identification of a person.

\section{LIST OF ABBREVIATIONS}

$\mathrm{Cm}$; centimeters, CT; computerized Tomography, CBCT; Cone beam computerized Tomography, etc; etcetera, mm; millimeters, \%; per cent, USA; United States of America.

Conflict of Interests: None 


\section{REFERENCES}

1- Sobol J, Ptaszyńska-Sarosiek I, Charuta A, Oklota-Horba M, Żaba C, Niemcunowicz-Janica A (2015) Estimation of age at death: examination of variation in cortical bone histology within the human clavicle. Folia Morphol (Warsz).; 74 (3): 378-88.

2- Liu YF, Wang R, Baur DA, Jiang XF (2018) A finite element analysis of the stress distribution to the mandible from impact forces with various orientations of third molars. J Zhejiang Univ Sci B., 19(1): 38-48.

3- Hu KS, Koh KS, Han SH, Shin KJ, Kim HJ (2006) Sex determination using nonmetric characteristics of the mandible in Koreans. J Forensic Sci., 51(6): 1376-82.

4- Sairam V, Geethamalika MV, Kumar PB, Naresh G, Raju GP (2016) Determination of sexual dimorphism in humans by measurements of mandible on digital panoramic radiograph. Contemp Clin Dent. 7 (4): 434-439.

5- Cunha E, Baccino E, Martrille L, Ramsthaler F, Prieto J, Schuliar Y, Lynnerup N, Cattaneo C (2009) The problem of aging human remains and living individuals: a review. Forensic SciInt 193(1-3):1-13.

6- Franklin D, Cardini A (2007) Mandibular morphology as an indicator of human subadult age: interlandmark approaches. J Forensic Sci 52(5):1015-1019.

7- Ishwarkumar S, Pillay P, Haffajee MR, Satyapal KS (2017) Morphometric analysis of the mandible in the Durban Metropolitan population of South Africa. Folia Morphol (Warsz).; 76 (1): 82-86.

8- Baghdadi, Z.D. and Pani, S.C.(2011) Accuracy of population-specific Demirjian curves in the estimation of dental age of Saudi children. Int. J. Paediatr Dent.pp. 125-31.

9- Motawei SM, Wahba BA, Aboelmaaty WM, Tolba EM (2016) Assessment of frontal sinus dimensions using CBCT to determine sexual dimorphism amongst Egyptian population. Journal of Forensic Radiology and Imaging 6: 8-13.

10- Caruso S, Storti E, Nota A, Ehsani S, Gatto R (2017) Temporomandibular Joint Anatomy Assessed by CBCT Images. Biomed Res Int.; 2017: 2916953.

11- De Oliveira FT, Soares MQ, Sarmento VA, Rubira CM, Lauris JR, Rubira-Bullen IR (2015) Mandibular ramus length as an indicator of chronological age and sex. Int $\mathrm{J}$ Legal Med., 129 (1):195-201.

12- Belaldavar C, Kotrashetti VS, Hallikerimath SR, Kale AD (2014) Assessment of frontal sinus dimensions to determine sexual dimorphism among Indian adults. J Forensic Dent Sci., 6(1): 25-30.
13- Holmes MA, Ruff CB (2011) Dietary effects on development of the human mandibular corpus. Am J PhysAnthropol., 145 (4): 615-28.

14- Silva LP, Leite RB1, Sobral APV, Arruda JA, Oliveira LV, Noronha MS, Kato CO, Mesquita RA, Schuch LF, Gomes APN, Vasconcelos ACU, Souza LB (2017) Oral and Maxillofacial Lesions Diagnosed in Older People of a Brazilian Population: A Multicentric Study. J Am Geriatr Soc. 65 (7): 1586- 1590.

15- Ichijo Y, Takahashi Y, Tsuchiya M, Marushita Y, Sato T, Sugawara H, Hayashi S, Itoh M, Takahashi T (2016) Relationship between morphological characteristics of hyoid bone and mandible in Japanese cadavers using threedimensional computed tomography. AnatSci Int. 91(4): 371-381.

16- Filho J, Manzi FR, de Freitas DQ, Bóscolo FN, de Almeida SM (2007) Evaluation of temporomandibular joint in stress-free patients. DentomaxillofacRadiol. 36 (6): 336340 .

17- More CB, Vijayvargiya R, Saha N (2017) Morphometric analysis of mandibular ramus for sex determination on digital orthopantomogram. J Forensic Dent Sci. 9 (1):1-5.

18- Weinberg SM, Parsons TE, Raffensperger ZD, Marazita ML (2015) Prenatal sex hormones, digit ratio, and face shape in adult males. OrthodCraniofac Res., 18 (1): 21-6.

19- Coquerelle M, Bookstein FL, Braga J, Halazonetis DJ, Weber GW, Mitteroecker P (2011) Sexual dimorphism of the human mandible and its association with dental development. Am J PhysAnthropol., 145 (2):192-202.

20- Kasperk C, Helmboldt A, Börcsök I, Heuthe S, Cloos O, Niethard F, Ziegler R (1997) Skeletal site-dependent expression of the androgen receptor in human osteoblastic cell populations. Calcif Tissue Int., 61(6): 464-473.

21- Cattaneo C, De Angelis D, Ruspa M, Gibelli D, Cameriere R, Grandi M (2008) How old am I? Age estimation in living adults: a case report. J Forensic Odontostomatol. 26 (2): 39-43.

22- Mohamad NV, Soelaiman IN, Chin KY (2016) A concise review of testosterone and bone health. ClinInterv Aging. 11:1317-1324. eCollection 2016.

23- Rai B, Krishan K, Kaur J, Anand SC (2008) Technical note: Age estimation from mandible by lateral cephalogram: a preliminary study. J Forensic Odontostomatol., 26 (1): 24-28.

24- Hazari P, Hazari RS, Mishra SK, Agrawal S, Yadav M (2016) Is there enough evidence so that mandible can be used as a tool for sex dimorphism? A systematic review. J Forensic Dent Sci., 8 (3): 174. 